\title{
Parameter Pengukuran Ventrikel Kiri menggunakan Ekokardiografi \\ Bagian 2
}

\section{Update rekomendasi tahun 2015 dari American Society of Echocardiography dan European Association of Cardiovascular Imaging}

Ario Suryo

\section{Fungsi regional ventrikel kiri}

Model pembagian segmen Vki digunakan dalam praktek klinis sehari-hari. Model pembagian menjadi 17 segmen direkomendasikan untuk menilai perfuso miokardial dengan menggunakan ekokardiografi dan teknik atau modalitas pencitraan lainnya . ( PET Scan atau Cardiac MRI). Model ini dapat dilihat pada gambar 4

Model 16 segmen direkomendasikan dipakai secara rutin untuk menilai gerakan dinding Vki karena gerakan endokardial dan penebalan pada bagian apeks Vki sulit untuk bisa dideteksi. Untuk menilai gerakan dinding ini , setiap segmen sebaiknya di dievaluasi menggunakan berbagai pandangan dan 4 tingkatan penilaian digunakan yaitu (1) normal atau hiperkinetik, (2) hipokinetik, (3) akinetik (tidak adanya

\section{Alamat Korespondensi}

dr. Ario Suryo, Departemen Kardiologi dan Kedokteran Vaskular FKUI, dan Pusta Jantung Nasional Harapan Kita, Jakarta. E-mail: arioskoe@yahoo.com penebalan miokard atau penebalan minimal), dan diskinetik (penipisan saat sistolik atau penipisan).

\section{Massa Ventrikel kiri}

Massa Vki merupakan salah satu faktor risiko penting dan predictor kuat terhadap kejadian kardiovaskular. Terdapat beberapa metode pengukuran massa Vki dari menggunakan modalitas M-mode, 2DE dan 3DE. Semua pengukuran tersebut dilakukan pada akhir fase diastolik. Semua metode tersebut akan mengkonversi volume menjadi massa dengan mengkalikan hasil pengukurannya dengan nilai densitas miokardial (sekitar $1.05 \mathrm{~g} / \mathrm{mL}$ ). Berikut ini adalah metode beserta kelebihan dan kekuranngannya .

\section{I. Metode Linear}

Metode ini menggunakan modalitas $\mathrm{M}$-mode yang dilakukan pada pandangan PLAX dimana dilakukan pemotongan setinggi ujung katup mitral tegak lurus dengan sumbu panjang Vki. Metode ini juga bisa dilakukan dengan melakukan pemotongan pada 


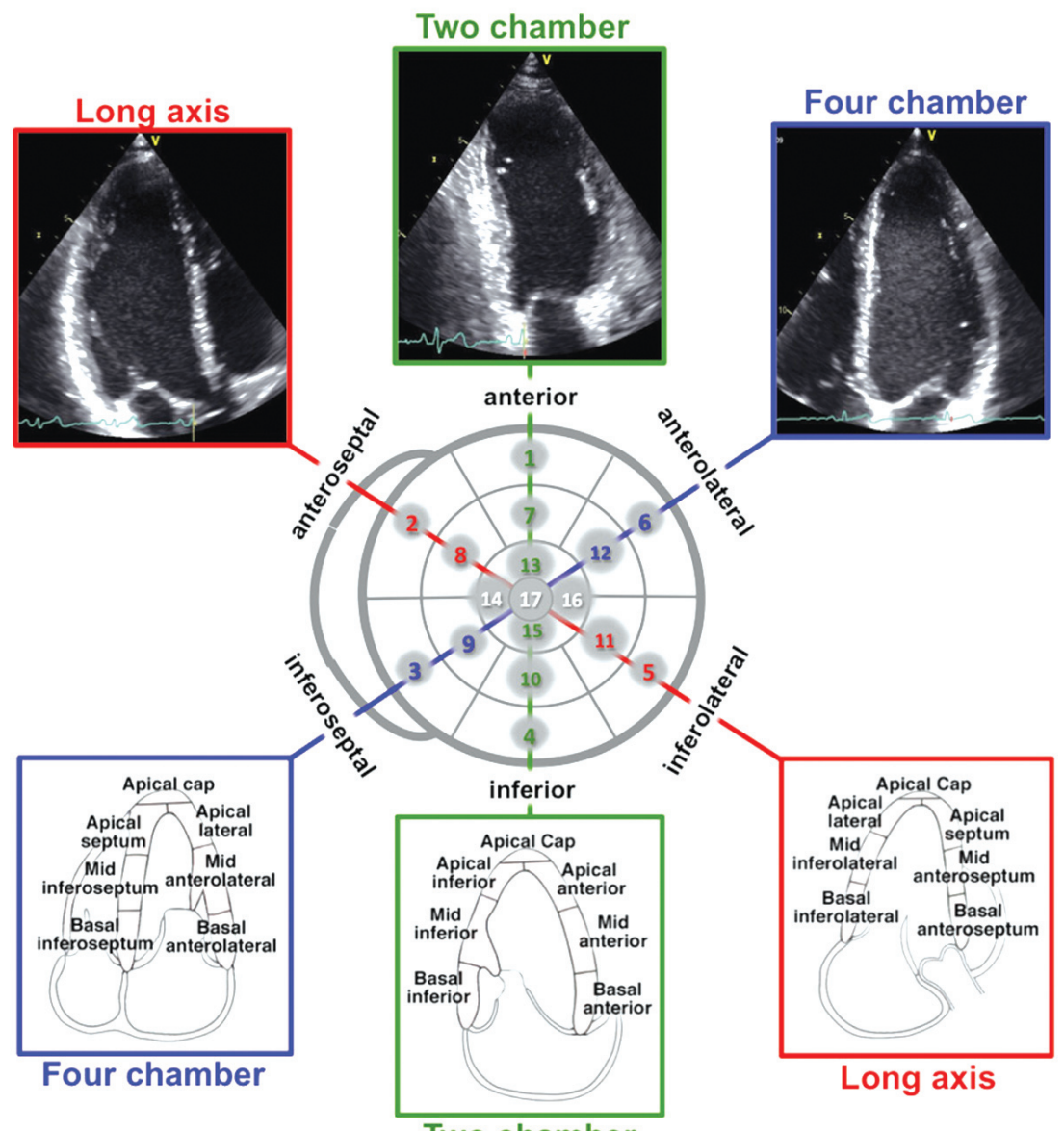

Gambar 4. Pembagian area miokardial Vki dari ekokardiografi
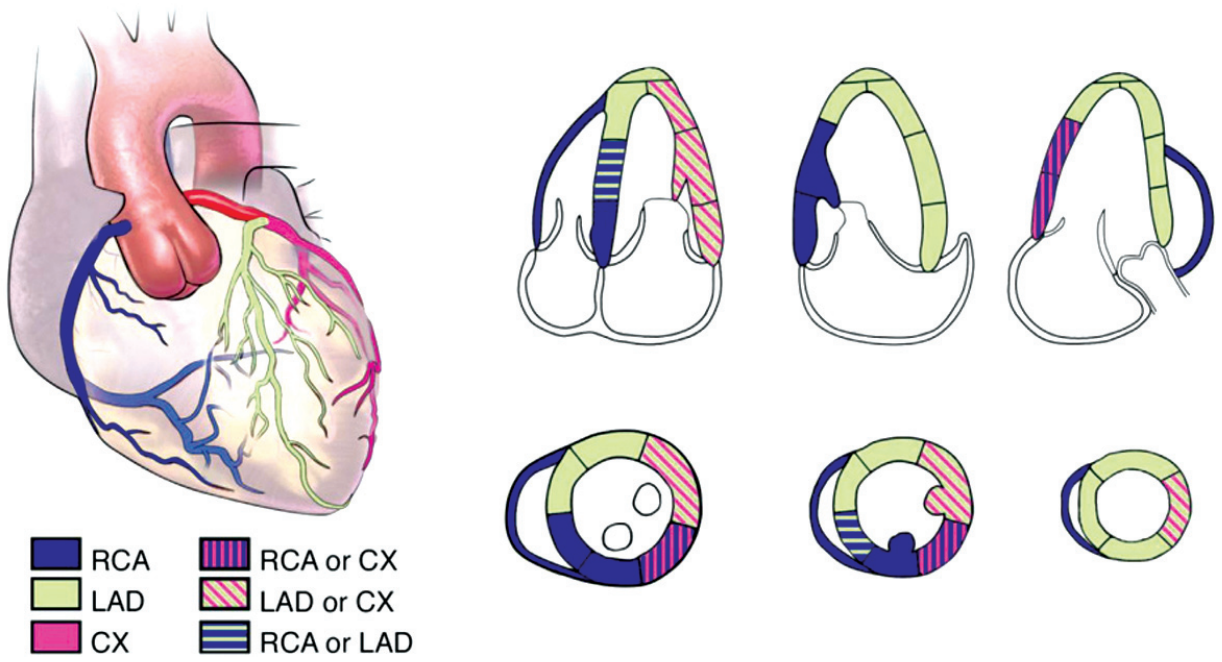

Gambar 5. Distribusi koroner sesuai dengan area pada gambaran potongan jantung yang di dapatkan dari ekokardiografi 
pandangan SAX segmen basal. Dilakukan pengukuran dan perhitungan menggunakan rumus :

$$
\begin{gathered}
\text { Mass LV }=0.8 \times 1.04 \times\left(\text { IVS }+ \text { LVID }+P W T^{3}-\right. \\
\text { LVID } \left.^{3}\right)+0.6 \mathrm{~g}
\end{gathered}
$$

IVS = interventricular septum

$\mathrm{LVID}=$ LV internal diameter

$\mathrm{PWT}=$ inferolateral wall thickness

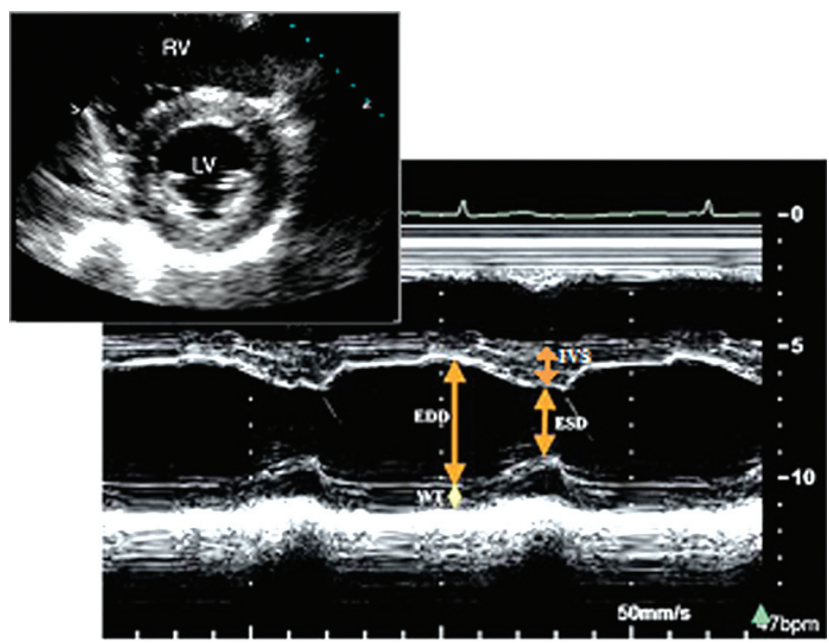

Gambar 6. Metode pemeriksaan dengan linear / M -mode

\section{Keuntungan :}

- mudah digunakan dan dipakai secara luas

- banyak data yang telah dipublikasi menggunakan metode ini

- memberikan nilai prognostic

- cukup akurat pada ventrikel dengan bentuk yang normal (misalnya kasus hipertensi, stenosis aorta)

- mudah digunakan sebagai metode skrining pada populasi yang besar

Keterbatasan:

- berdasarkan pada asumsi bahwa Vki berbentuk ellipsoid dengan perbandingan sumbu panjang / pendek adalah 2:1 dengan distribusi hipertrofi yang simetris

- arah sinar sering kali tidak tegak lurus sumbu Vki

- Dikarenakan pengukuran linear berbentuk kubus, kesalahan kecil pada pengukuran dimensi atau ketebalan berakibat kesalahan hasil perhitungan akhir
- Nilai massa Vki yang lebih dari sebenarnya (overestimate)

- Hasil yang tidak akurat pada keadaan hipertrofi asimetrik, dilatasi Vki dan kondisi lainnya dengan ketebalan Vki yang berbeda (distribusi tidak merata).

\subsection{Metode 2DE}

Pengukuran massa Vki menggunakan metode 2DE meliputi metode pengukuran dari 2DE secara langsung Truncated ellipsoid dan area length dengan melibatkan pemakaian formula untuk mendapatkan volume massa Vki.

\subsubsection{Metode dengan 2DE secara langsung}

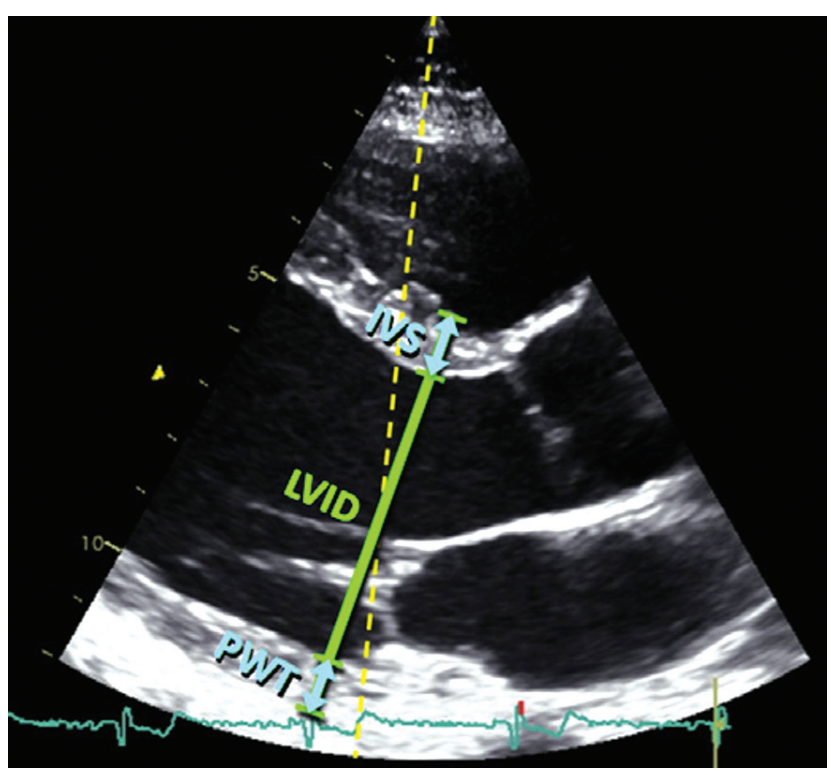

Gambar 7. Penilaian massa Vki dengan metode 2DE

Keuntungan :

- orientasi pengukuran disesuaikan agar supaya tegak lurus dengan sumbu panjang Vki

Keterbatasan

- berdasar pada asumsi geometris yang sama seperti halnya metode linear

- keterbatasan yang sama seperti halnya metode linear pada geometri Vki yang abnormal

- Nilai normal dengan metode ini tidak sebanyak seperti halnya metode Linear

- Dampak pencitraan harmonis terhadap penilaian 
massa Vki dan nilai normal masih perlu di telaah lebih jauh

\subsubsection{Truncated ellipsoid (penilaian berdasar} 2DE)

Penilaian massa Vki didasarkan perhitungan dengan menggunakan rumus :

$$
\begin{aligned}
\text { LV mass } & =1.05 \pi\left\{(b+t)^{2}\right. \\
& {\left[\frac{2}{3}(a+t)+d-\frac{d^{3}}{3(a+t)^{2}}\right] } \\
& \left.-b^{2}\left[\frac{2}{3} a+d-\frac{d^{3}}{3 a^{2}}\right]\right\}
\end{aligned}
$$

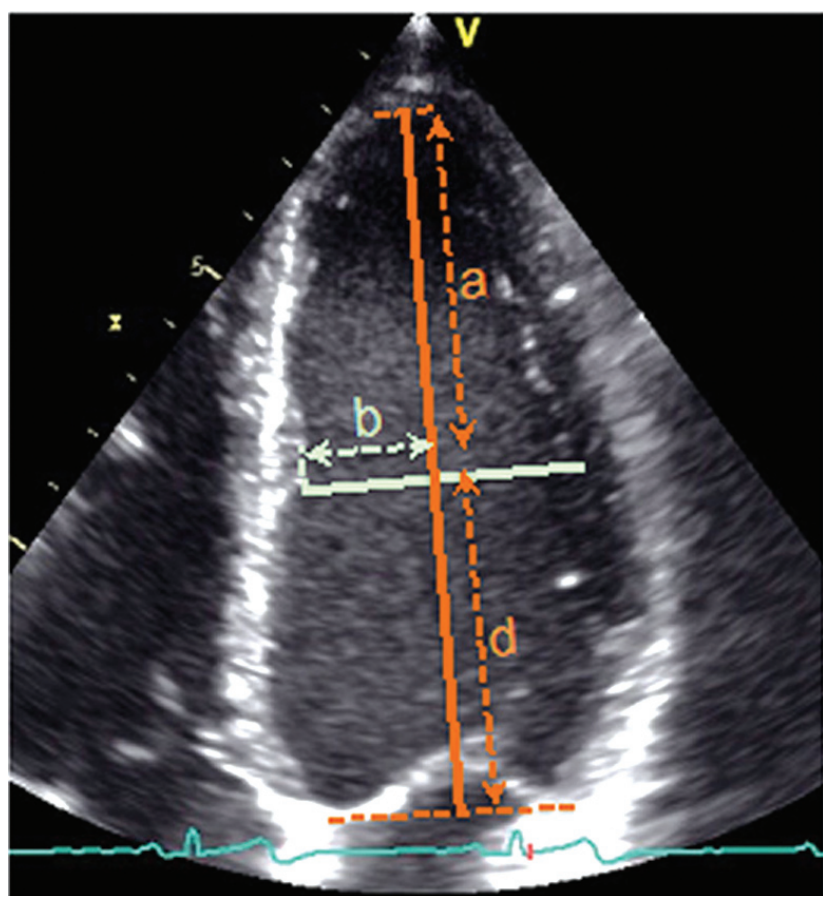

Gambar 8. Pengukuran Massa Vki menggunakan metode Truncated ellipsoid

\subsubsection{Area - length}

Massa LV :

Rerata ketebalan Vki dikalkulasikan dari potongan melintang dari Epikardial $\left(A_{1}\right)$ dan endokardial $\left(A_{2}\right)$ yang didapatkan dari SAX setinggi otot papilaris, dimana otot papilaris dianggap sebagai bagian dari

$$
\begin{aligned}
\text { LV mass }= & 1.05 \\
& \left\{\left[\frac{5}{6} A_{1}(a+d+t)\right]\right. \\
& \left.-\left[\frac{5}{6} A_{2}(a+d)\right]\right\}
\end{aligned}
$$

rongga Vki.

Radius dari potongan melintang ini dinilai dengan:

$$
b \sqrt{\frac{A_{2}}{\pi}}
$$

Kemudian rerata ketebalan dinding dikalkukasi menggunakan :

$$
t=\left(\sqrt{\frac{A_{1}}{\pi}}\right)-\mathrm{b}
$$
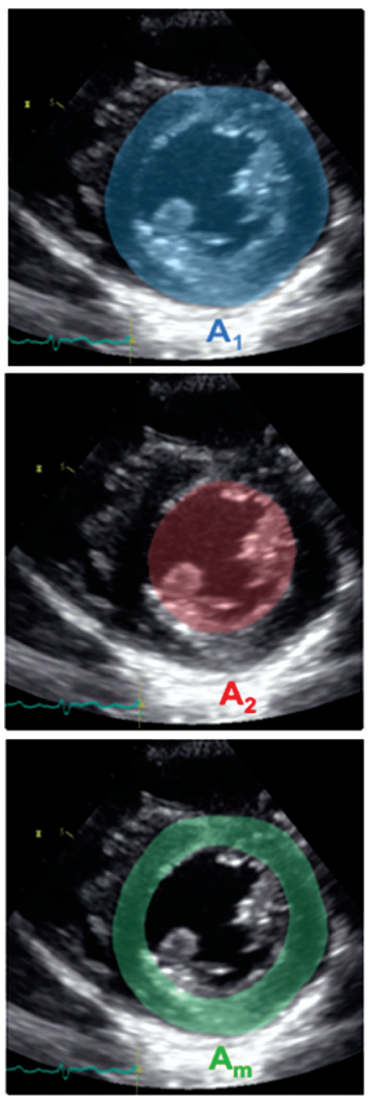

Gambar 9. Pengukuran massa Vki menggunakan metode area length 
Suryo A: Parameter pengukuran ventrikel kiri menggunakan ekokardiografi

Tabel 3. Nilai normal untuk dimensi Vki, volume dan massa Vki dengan berbagi metode yang sudah dijelaskan sebelumnya.

\begin{tabular}{|c|c|c|c|c|c|c|c|c|}
\hline & \multicolumn{4}{|c|}{ Mab } & \multicolumn{4}{|c|}{ Fornalo } \\
\hline & $\begin{array}{l}\text { Normal } \\
\text { rango }\end{array}$ & $\begin{array}{l}\text { Mildly } \\
\text { abnormal }\end{array}$ & $\begin{array}{l}\text { Modbratoly } \\
\text { abnoemal }\end{array}$ & $\begin{array}{l}\text { Soveroly } \\
\text { abnormal }\end{array}$ & $\begin{array}{c}\text { Normal } \\
\text { ange }\end{array}$ & $\begin{array}{l}\text { Milidly } \\
\text { abnormal }\end{array}$ & $\begin{array}{l}\text { Modbratuly } \\
\text { abnomal }\end{array}$ & $\begin{array}{l}\text { Soverdy } \\
\text { abnormal }\end{array}$ \\
\hline \multicolumn{9}{|l|}{ LV dimensibn } \\
\hline LVdiastolic diameter $(\mathrm{cm})$ & $4.2-5.8$ & $5.9-6.3$ & $6.4-6.8$ & $>6.8$ & $3.8-5.2$ & $5.3-5.6$ & $5.7-6.1$ & $>6.1$ \\
\hline LV disatolic diameter/BSA $\left(\mathrm{cm} / \mathrm{m}^{2}\right)$ & $2.2-3.0$ & $3.1-3.3$ & $3.4-3.6$ & $>3.6$ & $2.3-3.1$ & $3.2-3.4$ & $3.5-3.7$ & $>3.7$ \\
\hline LVsystolic diameter (cm) & $2.5-4.0$ & $4.1-4.3$ & $4.4-4.5$ & $>4.5$ & $2.2-3.5$ & $3.6-3.8$ & $3.9-4.1$ & $>4.1$ \\
\hline LVsystolic diameter/BSA $\left(\mathrm{cm}^{2} \mathrm{~m}^{2}\right)$ & $1.3-2.1$ & $2.2-2.3$ & $2.4-2.5$ & $>2.5$ & $1.3-2.1$ & $2.2-2.3$ & $2.4-2.6$ & $>2.6$ \\
\hline \multicolumn{9}{|l|}{ LV volume } \\
\hline LVdiastolic volume $(\mathrm{mL})$ & $62-150$ & $151-174$ & $175-200$ & $>200$ & $46-106$ & $107-120$ & $121-130$ & $>130$ \\
\hline LV disstollc volume/BSA $\left(\mathrm{mL} / \mathrm{m}^{2}\right)$ & $34-74$ & $75-89$ & $90-100$ & $>100$ & $29-61$ & $62-70$ & $71-80$ & $>80$ \\
\hline LVsystolic volume $(\mathrm{mL})$ & $21-61$ & $62-73$ & $74-85$ & $>85$ & $14-42$ & $43-65$ & $56-67$ & $>67$ \\
\hline LV systolic volume $B S A\left(\mathrm{~mL}^{\prime} \mathrm{m}^{2}\right)$ & $11-31$ & $32-38$ & $39-45$ & $>-45$ & $8-24$ & $25-32$ & $33-40$ & $>40$ \\
\hline \multicolumn{9}{|l|}{ LV function } \\
\hline $\operatorname{LVEF}(\%)$ & $52-72$ & $41-61$ & $30-40$ & $<0$ & $54-74$ & $41-53$ & $30-40$ & $\ll 0$ \\
\hline \multicolumn{9}{|l|}{ LV mass by Inear method } \\
\hline Septal wall thickness $(\mathrm{cm})$ & $0.6-1.0$ & $1.1-1.3$ & $1.4-1.6$ & $>1.6$ & $0.6-0.9$ & $1.0-1.2$ & $1.3-1.5$ & $>1.5$ \\
\hline Posterior wall thickness $(\mathrm{cm})$ & $0.6-1.0$ & $1.1-1.3$ & $1.4-1.6$ & $>1.6$ & $0.6-0.9$ & $1.0-1.2$ & $1.3-1.5$ & $>1.5$ \\
\hline LVmass (g) & $88-224$ & $225-258$ & $259-292$ & $>292$ & $67-162$ & $163-186$ & $187-210$ & $>210$ \\
\hline LVmass/BSA $\left(g / m^{2}\right)$ & $49-115$ & $116-131$ & $132-148$ & $>148$ & $43-95$ & $96-108$ & $109-121$ & $>121$ \\
\hline \multicolumn{9}{|l|}{ LV mass by $2 D$ method } \\
\hline LVmass (g) & $96-200$ & $201-227$ & $228-254$ & $>254$ & $66-150$ & $151-171$ & $172-193$ & $>193$ \\
\hline LVmass/BSA $\left(g / m^{2}\right)$ & $50-102$ & $103-116$ & $117-130$ & $>130$ & $44-88$ & $89-100$ & $101-112$ & $>112$ \\
\hline
\end{tabular}

Dan area potongan melintang miokardium $\left(\mathrm{A}_{\mathrm{m}}\right)$ pada pandangan SAX adalah:

$$
A_{m}=A_{1}-A_{2}
$$

Massa Vki dikalkukasikan dari penilaian itu ditambah panjang Vki dihitung dari potongan melintang setinggi basal (b) sampai dengan apeks (a).

Massa Vki $=($ volume epikardial Vki - Volume endokardial Vki) x 1.05 = volume miokardial $\times 1.05$

Keuntungan :

- koreksi parsial terhadap distorsi bentuk Vki

- lebih kurang tergantung kepada asumsi geometri dibandingkan pengukuran secara linear

Keterbatasan :

- diperlukan kualitas gambar yang baik dan pandangan PLAX yang tepat (hindari bidang yang miring atau oblik)

- diperlukan batas epikardial yang jelas

- metode yang kurang praktis

- variabilitas pengukuran yang lebih tinggi

- masih kurangnya data normative yang telah dipublikasikan

- terbatasnya data prognostic
Metode dengan 3DE

Keuntungan :

- pengukuran secara langsung tanpa memakai asumsi geometris terhadap bentuk rongga jantung dan distribusi hipertrofi

- lebih akurat dari pada pengukuran linear atau metode 2DE

- Nilai penghitungan ulang lebih baik

- Lebih baik untuk menilai perubahan nilai yang kecil pada satu pasien yang sama

Keterbatasan :

- nilai normal masih kurang banyak dilaporkan

- tergantung kepada kualitas pencitraan yang dihasilkan

- memerlukan pasien yang mampu bekerja sama saat pemeriksaan

\section{Daftar Pustaka}

1. Lang RM,Badano LP, Mor-Avi V, Afilalo J, Amstrong A et al. J Am Soc Echocardiogr 2015;28:1-39

2. Anderson B. Echocardiography: normal examination and echocardiographic measurements $2^{\text {nd }}$ revised edition, Cardiotext, 2007 